\title{
Effect of Nicotinic Acid-induced Insulin Resistance on Pancreatic B Cell Function in Normal and Streptozocin-treated Baboons
}

David K. McCulloch, Steven E. Kahn, Michael W. Schwartz, Donna J. Koerker, and Jerry P. Palmer Veterans Administration Medical Center, Department of Medicine, Diabetes Endocrinology Research Center, University of Washington, Seattle, Washington 98108

\begin{abstract}
To study the interaction between insulin secretion and insulin action in maintaining glucose homeostasis, we induced experimental insulin resistance in eight normal baboons, in six baboons treated with $40 \mathrm{mg} / \mathrm{kg}$ streptozocin (STZ-40), and in six baboons treated with $200 \mathrm{mg} / \mathrm{kg}$ streptozocin (STZ-200). Insulin resistance was induced by a 20-d continuous intravenous infusion of nicotinic acid (NA). Normal animals showed compensatory increases in several measures of insulin secretion (fasting insulin [FI], acute insulin response to arginine [AIR $\mathbf{R}_{\text {arg }}$, acute insulin response to glucose [AIR gind, $_{\text {and }}$ glucose potentiation slope $\left.\left[\Delta \mathrm{AIR}_{\text {arg }} / \Delta G\right]\right)$, with no net change in fasting plasma glucose (FPG) or glycosylated hemoglobin $\left(\mathrm{HbA}_{1 \mathrm{c}}\right)$. STZ-40 animals showed compensatory increases in FI, AIR ars, and $A I R_{\text {gluc }}$, but $\Delta A I R_{\text {arg }} / \Delta G$ failed to compensate. Although FPG remained normal in this group during NA infusion, $\mathbf{H b A}_{1 c}$ rose significantly. STZ-200 animals failed to show compensatory changes in both $\mathrm{AIR}_{\text {eluc }}$ and $\Delta A I R_{\text {arg }} / \Delta G$, with both $\mathrm{HbA}_{1 \mathrm{c}}$ and FPG rising. These animals showed a paradoxical inhibition of insulin secretion in response to intravenous glucose during NA infusion, at a time when they were hyperglycemic. These data indicate that a significant degree of insulin resistance does not cause hyperglycemia in the presence of normal $B$ cell function but, in animals with reduced $B$ cell mass and superimposed insulin resistance, the degree of hyperglycemia is proportional to the degree of pancreatic B cell dysfunction. (J. Clin. Invest. 1991. 87:1395-1401.) Key words: nicotinic acid • insulin resistance • streptozocin • B cell dysfunction • hyperglycemia - baboon
\end{abstract}

\section{Introduction}

Investigation of the interaction between insulin secretion and insulin action in maintaining glucose homeostasis is fundamental to understanding the pathophysiology of many types of diabetes mellitus. Non-insulin-dependent diabetes (NIDDM) ${ }^{1}$ is a heterogenous disorder involving defects in both insulin

Address reprint requests to Dr. McCulloch, Medical Services (111), Veterans Administration Medical Center, 1660 S. Columbian Way, Seattle, WA 98108.

Received for publication 6 July 1990 and in revised form 9 November 1990.

1. Abbreviations used in this paper: $\mathrm{AIR}_{\text {arg }}$ and $\mathrm{AIR}_{\text {eluc }}$, acute insulin response to arginine and glucose, respectively; $\Delta \mathrm{AIR}_{\text {and }} / \Delta \mathrm{G}$, glucose potentiation slope of $\mathrm{AIR}$ arg $; \mathrm{FI}$, fasting insulin; $\mathrm{HbA}_{\mathrm{lc}}$, glycosylated hemoglobin; IDDM, insulin-dependent diabetes mellitus; NA, nicotinic acid; NIDDM, non-insulin-dependent diabetes mellitus; $\mathrm{S}_{\mathbf{1}}$, insulin sensitivity index; STZ, streptozocin.

The Journal of Clinical Investigation, Inc.

Volume 87, April 1991, 1395-1401 secretion and insulin action (1). In insulin-dependent diabetes (IDDM) the acute presentation of hyperglycemia usually occurs when increased insulin resistance, intercurrent illness, or puberty are superimposed on subclinical B cell dysfunction.

We wished to test the hypothesis that, whereas normal pancreatic islets are able to adapt to periods of insulin resistance, those with $B$ cell dysfunction may be unable to increase insulin secretion sufficiently to maintain normoglycemia. As a model for graded B cell dysfunction, we have used streptozocin (STZ)treated adolescent baboons (2). We have previously shown that, at low doses of STZ, the changes in pancreatic B cell function in these animals are similar to those seen in nondiabetic first-degree relatives of IDDM patients during the preclinical period of $\operatorname{IDDM}(3,4)$. We have also shown that higher doses of STZ induce clinical states of non-insulin-requiring or insulin-requiring diabetes, and that the degree of B cell dysfunction measured in vivo within $3 \mathrm{~d}$ of sacrifice correlates closely with the quantitative estimates of overall $B$ cell mass and pancreatic insulin content measured in the same animals (5).

In determining whether normal or STZ-treated animals are capable of adapting to periods of insulin resistance, it is necessary to choose an agent that causes a reversible reduction in peripheral insulin action without having direct effects on the pancreatic B cell. Nicotinic acid (NA), the B group vitamin used in long-term treatment of some of the hyperlipidemic syndromes, fulfills these requirements. Acutely (within a few hours) NA lowers plasma free fatty acid levels (6-9) resulting in improved insulin action (10-12). However, during prolonged administration of NA (several days) free fatty acid levels are increased (13). Since the increased availability of free fatty acids markedly impairs glucose utilization in muscle and other tissues (14-16), this is the likely explanation for the insulin resistance associated with long-term NA treatment (17-21). Treatment of normal men with 2 wk of oral NA (up to $2 \mathrm{~g} / \mathrm{d}$ ) was associated with a twofold increase in basal and stimulated insulin levels and a profound reduction in insulin sensitivity (21). That these changes are not due to direct stimulation of the islets by NA has been shown both in perfusion studies of rat islets (22) and in pancreatic rat slices (23) where NA, even in high concentrations, both under basal conditions and during maximal stimulation by glucose, glucagon, or theophylline, did not enhance insulin secretion.

We have therefore determined the effect of prolonged NA infusion on insulin sensitivity, pancreatic B cell function, fasting, and postprandial glycemia in normal adolescent baboons and in those with STZ-induced subclinical B cell dysfunction.

\section{Methods}

Animals

These studies were carried out on conscious adolescent male baboons (Papio cyanocephalus/anubis), weighing 8-14 kg, which were adapted 
to living in primate tethers. Silastic catheters, permanently implanted in the vena cava through either the jugular or femoral vein were kept patent by a continuous infusion of $150 \mathrm{mmol} / \mathrm{liter} \mathrm{NaCl}$ and $5 \mathrm{U} / \mathrm{ml}$ heparin at the rate of $80-100 \mathrm{ml} / 24 \mathrm{~h}$. At least $7 \mathrm{~d}$ of recovery time after catheter implantation were allowed before initiation of the studies. The catheters extended outside the cages, allowing frequent blood sampling as well as infusion of test substances without disturbing the animals. Except for the day of study, animals were fed two equal meals at 0800 and 1300 hours. The study was approved by the University of Washington Regional Primate Center's Experimental Studies Review Committee.

\section{Materials}

STZ and NA were obtained from Sigma Chemical Co., St. Louis, MO. NA was prepared as a $0.1 \%$ solution. Arginine hydrochloride was obtained from Cutter Laboratories, Sacramento, CA, prepared at a $10 \%$ solution. Somatostatin was obtained from Bachem Inc., Torrance, CA.

\section{$S T Z$ treatment}

STZ was given in the fasting state as an intravenous injection. A total of 10 animals were used as outlined in Table I. Six animals received a single dose of $40 \mathrm{mg} / \mathrm{kg}$ (STZ-40). Six animals received two additional doses of $80 \mathrm{mg} / \mathrm{kg}$, separated by at least $1 \mathrm{wk}$, giving a cumulative dose of $200 \mathrm{mg} / \mathrm{kg}$ (STZ-200) for these animals. There were eight normal, six STZ-40, and six STZ-200 animals. There were no significant differences in weight among the groups. All experiments were performed at least $1 \mathrm{wk}$ after the last dose of STZ

\section{$N A$ treatment}

NA was given as a continuous intravenous infusion at a dose of 60 $\mathrm{mg} / \mathrm{kg}$ per d for $10 \mathrm{~d}$ followed by $120 \mathrm{mg} / \mathrm{kg}$ per $\mathrm{d}$ for a further $10 \mathrm{~d}$. At each stage (normal, STZ-40, or STZ-200) animals had B cell function and insulin sensitivity measured within $3 \mathrm{~d}$ before commencing the NA infusion and again during the last $3 \mathrm{~d}$ of the higher-dose NA infusion.

\section{$B$ cell function tests}

These tests were carried out after an 18-h overnight fast. Samples were drawn into tubes containing EDTA and Trasylol, placed on ice, and centrifuged within $10 \mathrm{~min}$. Arginine stimulation, both at basal glucose and during hyperglycemic clamp, glucose stimulation, and measurement of insulin sensitivity were performed. All studies were carried out on a single day with glucose stimulation and insulin sensitivity measurements obtained between the basal arginine stimulation and the hyperglycemic clamp. Plasma was then frozen until assayed for immunoreactive insulin. At the end of the study, the red cells were resuspended in $150 \mathrm{mmol} /$ liter $\mathrm{NaCl}$ and reinfused into the animal.

Table I. Explanation of Which Animals Were Studied at Each Stage

\begin{tabular}{cccc}
\hline Animal no. & Normal & STZ-40 & STZ-200 \\
\hline 1 & + & - & - \\
2 & + & + & + \\
3 & + & - & - \\
4 & + & + & + \\
5 & + & + & + \\
6 & + & + & + \\
7 & + & - & + \\
8 & + & + & + \\
9 & - & + & - \\
10 & - & 6 & 6 \\
Total & 8 & & \\
\hline
\end{tabular}

Symbols: + , the animal was studied at this stage; - , the animal was not studied at this stage.
Arginine stimulation. Insulin secretory responses to intravenous arginine were measured at two different plasma glucose levels. At each level three prestimulus blood samples were obtained $10 \mathrm{~min}, 5 \mathrm{~min}$, and immediately before administration of arginine. A dose of $0.07 \mathrm{~g} / \mathrm{kg}$ $10 \%$ arginine hydrochloride was administered intravenously in $30 \mathrm{~s}$, the beginning of which was designated time zero. Blood samples were obtained 2, 3, 4, and $5 \mathrm{~min}$ after arginine administration. $3 \mathrm{~h}$ later (after the intravenous glucose tolerance test; see below) a variable rate infusion of $50 \%$ dextrose was delivered by a syringe pump (model 355 , Sage Instruments, Cambridge, MA) in order to raise and maintain the plasma glucose level at $\sim 14.0 \mathrm{mmol} /$ liter. Blood samples $(0.5 \mathrm{ml})$ were obtained every 3-5 min for plasma glucose measurement, and based on these values the glucose infusion rate was adjusted. $40 \mathrm{~min}$ after commencing the hyperglycemic clamp, a second arginine pulse $(0.07 \mathrm{~g} / \mathrm{kg})$ was given, and the insulin response was measured as before.

Insulin sensitivity testing. A modified intravenous glucose tolerance test was performed. Blood samples were obtained 10,5, and $2 \mathrm{~min}$ before glucose injection. Immediately after this sample was taken, an intravenous bolus of $200 \mu \mathrm{g}$ somatostatin was given, followed at time zero by a bolus of $0.3 \mathrm{~g} / \mathrm{kg} \mathrm{50 \%} \mathrm{dextrose.} \mathrm{Further} \mathrm{blood} \mathrm{samples} \mathrm{were}$ obtained $2,3,4,5,6,8,10,12,14,16,19,22,25,30,40,50,60,70,80$, $90,100,120,140,160$, and $180 \mathrm{~min}$ after glucose injection. From the glucose and insulin data an index of tissue insulin sensitivity $\left(\mathrm{S}_{\mathrm{I}}\right)$ was calculated using the minimal modeling technique of Bergman et al. (24). This modification with somatostatin has been shown to improve parameter identification and thereby increase the precision of the $S_{I}$ measurement (25). $S_{I}$ was measured in all normal and STZ-40 animals before and during the last $3 \mathrm{~d}$ of NA infusion. $S_{1}$ could not be measured in STZ-200 animals because there was insufficient insulin response to allow accurate modeling.

Glucose stimulation. An intravenous glucose tolerance test was performed. Blood samples were obtained $10 \mathrm{~min}, 5 \mathrm{~min}$, and immediately before glucose injection. A bolus of $0.3 \mathrm{~g} / \mathrm{kg} \mathrm{50 \%}$ dextrose was given in $30 \mathrm{~s}$ commencing at time zero. Further blood samples were obtained 2 , $3,4,5,6,8$, and $10 \mathrm{~min}$ after beginning the dextrose injection.

Analytical methods. Plasma insulin was assayed by a modification of the double-antibody method of Morgan and Lazarow (26). Plasma glucose was measured using a glucose analyzer (Beckman Instruments, Inc., Palo Alto, CA). All samples from an individual study were analyzed in duplicate in a single assay. Glycosylated hemoglobin $\left(\mathrm{HbA}_{1 \mathrm{c}}\right)$ was measured using a sensitive calorimetric thiobarbituric acid method (27).

Calculations and statistical analysis. Fasting plasma glucose and insulin were calculated as the mean of the three samples before the first arginine injection. The acute insulin response to glucose ( $\left.\operatorname{AIR}_{\text {gluc }}\right)$ was calculated as the mean of the poststimulus samples obtained at $2,3,4$, $5,6,8$, and $10 \mathrm{~min}$ after the intravenous glucose injection minus the mean of the three prestimulus samples. The acute insulin response to arginine at fasting plasma glucose ( $\mathrm{AIR}_{\text {arg }}$ ) was calculated as the mean of the poststimulus samples obtained at $2,3,4$, and 5 min minus the mean of the three prestimulus samples.

Since the $\mathrm{AIR}_{\text {arg }}$ increases in a linear manner in the range of plasma glucose from 5.56-16.7 mmol/liter (28), we calculated the slope of the increase in the $\mathrm{AIR}_{\text {arg }}$ as follows: $\left(\mathrm{AIR}_{\mathrm{arg}} \mathrm{h}-\mathrm{AIR}_{\text {arg }} \mathrm{l} / \Delta\right.$ plasma glucose, where $\mathrm{AIR}_{\mathrm{arg}} \mathrm{h}$ is the acute insulin response to arginine at the higher glucose level, $\mathrm{AIR}_{\text {arg }} l$ is the same calculation at the lower glucose level, and $\Delta$ plasma glucose is the difference between the two glucose levels.

Nonparametric statistics were used throughout using the Statview II program (Abacus Concepts, Inc., Berkeley, CA) on a Macintosh SE/ 30 computer. Comparison between any two groups (e.g., normals before NA vs. STZ-40 before NA) was tested using the Mann-Whitney U-test; for all three groups the Kruskal-Wallis one-way analysis of variance was employed. For changes within each group (before and during NA treatment), the Wilcoxon signed rank test was used.

\section{Results}

Insulin sensitivity. $\mathrm{S}_{\mathrm{I}}$ fell in all animals during NA infusion (Fig. 1); $S_{I}$ for normal animals before NA was $4.0 \pm 0.8 \times 10^{5}$ 

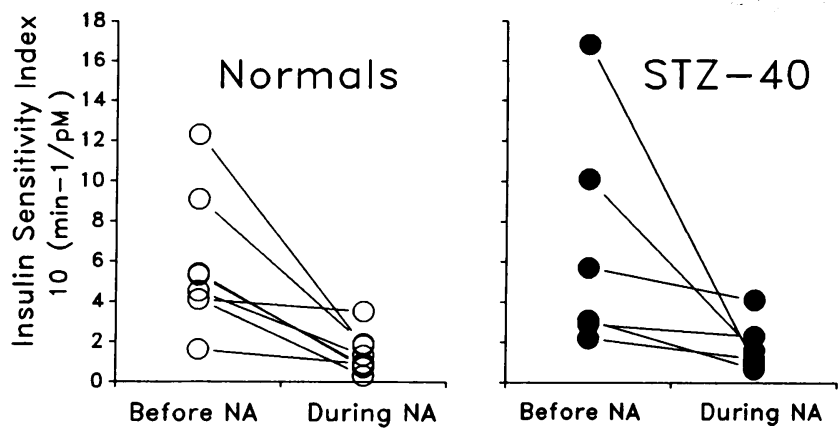

Figure 1. Changes in insulin sensitivity index before and during NA infusion in normal (o) and STZ-40 (•) animals.

$\left(\mathrm{min}^{-1} / \mathrm{pM}\right)$ and fell to $1.0 \pm 0.2 \times 10^{5}\left(\mathrm{~min}^{-1} / \mathrm{pM}\right), P<0.01$. For STZ-40 animals, $S_{1}$ before NA infusion was $4.6 \pm 1.6 \times 10^{5}$ $\left(\mathrm{min}^{-1} / \mathrm{pM}\right)$, not statistically different from normals. During NA infusion $\mathrm{S}_{\mathrm{I}}$ fell to $1.3 \pm 0.5 \times 10^{5}\left(\mathrm{~min}^{-1} / \mathrm{pM}\right), P<0.03$, in STZ-40 animals indicating that a similar degree of insulin resistance was induced in both groups.

Pancreatic $B$ cell function. In the normal animals treated with NA, fasting insulin (FI) increased about twofold (Table II). $\mathrm{AIR}_{\text {arg }}$ at basal glucose increased from $880 \pm 190$ to $1,730 \pm 488 \mathrm{pM}(P<0.07)$ (Fig. 2, left, upper panel $)$ and also during hyperglycemia clamp of $\sim 14 \mathrm{mM}$, from $2,769 \pm 582$ to $5,106 \pm 1044 \mathrm{pM}(P<0.03)$, as illustrated in Fig. 3, top panel. The slope of glucose potentiation of $\mathrm{AIR}_{\text {arg }}\left(\Delta \mathrm{AIR}_{\text {arg }} / \Delta G\right)$ therefore increased from $191 \pm 41$ to $361 \pm 85 \mathrm{pM}_{\mathrm{ins}} \cdot \mathrm{mM}_{\mathrm{gluc}}{ }^{-1}, P$ $<0.05$, (Table II and Fig. 3, upper panel). AIR eluc in the normal animals increased from $902 \pm 108$ to $1,703 \pm 408 \mathrm{pM}$ during NA infusion $(P<0.04)$ (Table II and Fig. 2, right, upper panel).

In the STZ-40 animals all of the measures of $B$ cell function before NA infusion were reduced by about a third but none were significantly different from those of the normal animals before NA infusion. During NA infusion, fasting insulin and $\mathrm{AIR}_{\text {arg }}$ at basal glucose increased significantly (Table II and Fig. 2 , left, middle panel). However, $\mathrm{AIR}_{\text {arg }}$ during hyperglycemic clamp failed to show a compensatory increase during NA infusion (Fig. 3, middle panel), such that $\Delta \mathrm{AIR}_{\mathrm{arg}} / \Delta \mathrm{G}$ remained unchanged (Table II). AIR $_{\text {gluc }}$ did show a compensatory in- crease in STZ-40 animals from $602 \pm 143$ to $1,173 \pm 322, P$ $<0.05$, (Table II and Fig. 2, right, middle panel). The changes in $\mathrm{AIR}_{\text {gluc }}$ and $\Delta \mathrm{AIR}_{\text {arg }} / \Delta \mathrm{G}$ during NA-induced insulin resistance are further illustrated in Fig. 4, for normal and STZ-40 animals. $\mathrm{S}_{\mathrm{I}}, \mathrm{AIR}_{\text {eluc }}$, and $\Delta \mathrm{AIR} \mathrm{R}_{\text {arg }} / \Delta \mathrm{G}$ have been obtained in a group of 29 normal animals. These animals spanned a wide range of $S_{1}$ (seven had $S_{1}$ of $<1.0$, five had $S_{1}$ of 1.0-1.9, six had $S_{1}$ of 2.0-2.9, four had $S_{1}$ of 3.0-4.9, three had $S_{I}$ of 5.0-7.9, and four had $\mathrm{S}_{\mathrm{I}}$ of 8.0-12.9). There is a significant inverse correlation between $\mathrm{S}_{\mathrm{I}}$ and $\mathrm{AIR}_{\text {gluc }}$ such that $\ln \mathrm{AIR}_{\text {gluc }}=5.09-0.37 \ln$ $\mathrm{S}_{\mathrm{I}}, r=0.56, P<0.001$. A similar relationship exists between $\mathrm{S}_{\mathrm{I}}$ and $\Delta \mathrm{AIR}_{\text {arg }} / \Delta \mathrm{G}\left(\ln \Delta \mathrm{AIR}_{\mathrm{arg}} / \Delta \mathrm{G}=5.47-0.46 \ln \mathrm{S}_{\mathrm{I}}, r=0.66, P\right.$ $<0.001)$. In Fig. 4 the curved lines show the mean \pm 1 SD for these normal animals and provide a setting in which to evaluate the changes seen in normal and STZ-40 animals during NA treatment. Both groups showed an appropriate increase in $\mathrm{AIR}_{\text {gluc }}$ as $\mathrm{S}_{\mathrm{I}}$ fell, such that they remained within the expected normal range (upper panel, Fig. 4). However, although the normal animals showed an appropriate compensatory increase in $\Delta \mathrm{AIR}_{\text {arg }} / \Delta \mathrm{G}$ to the reduction in $\mathrm{S}_{\mathrm{I}}, \mathrm{STZ}-40$ animals failed to do so, thereby falling outside the expected normal range (lower panel, Fig. 4).

The effects of STZ in reducing insulin secretion is evident over all three groups before NA, using the Kruskal-Wallis test. Reduction in $\operatorname{AIR}_{\text {arg }}(P<0.02), \operatorname{AIR}_{\text {gluc }}(P<0.002)$, and $\Delta \mathrm{AIR}_{\mathrm{arg}} / \Delta \mathrm{G}(P<0.002)$ were highly significant. Comparing STZ-200 animals with normals using the Mann-Whitney Utest, the fasting insulin, $\mathrm{AIR}_{\text {gluc }}, \mathrm{AIR}_{\text {arg }}$, and $\Delta \mathrm{AIR}_{\mathrm{arg}} / \Delta \mathrm{G}$ before NA were significantly lower than in normal animals before NA (Table II, $P<0.05$ ). During NA infusion there were slight, but statistically insignificant increases in fasting insulin and $\mathrm{AIR}_{\text {arg }}$ (Table II and Fig. 2, left, lower panel). In contrast, $\mathrm{AIR}_{\text {arg }}$ during hyperglycemic clamp showed a slight but significant decrease during NA infusion from $360 \pm 144$ to $276 \pm 132 \mathrm{pM}(P$ $<0.05$ ) such that $\Delta \mathrm{AIR}_{\text {arg }} / \Delta \mathrm{G}$ became negative (Table II, and Fig. 3, lower panel). After intravenous glucose there was also a paradoxical decrement in insulin secretion during NA infusion (Fig. 2, right, lower panel). In STZ-200 animals before NA, insulin rose from $96 \pm 12 \mathrm{pM}$ before intravenous glucose to remain elevated at $\sim 200 \mathrm{pM}$ from 2 to $6 \mathrm{~min}$. In STZ-200 animals during NA, basal insulin was $168 \pm 48 \mathrm{pM}$ before glu-

Table II. Changes in Pancreatic B Cell Function before and during Nicotinic Acid Infusion in Normal, STZ-40, and STZ-200 Animals

\begin{tabular}{|c|c|c|c|c|c|c|}
\hline & \multicolumn{2}{|c|}{ Normals $(n=8)$} & \multicolumn{2}{|c|}{$\operatorname{STZ}-40(n=6)$} & \multicolumn{2}{|c|}{ STZ-200 $(n=6)$} \\
\hline & Before NA & During NA & Before NA & During NA & Before NA & During NA \\
\hline & \multicolumn{2}{|c|}{$\underset{1}{N S}$} & \multicolumn{2}{|c|}{$\stackrel{0.03}{1}$} & \multicolumn{2}{|c|}{$\stackrel{\text { NS }}{\perp}$} \\
\hline \multirow[t]{2}{*}{ Fasting insulin $(p M)$} & $257 \pm 55$ & $536 \pm 224$ & $163 \pm 31$ & $550 \pm 155$ & $171 \pm 24$ & $230 \pm 41$ \\
\hline & \multicolumn{2}{|c|}{$\begin{array}{c}0.04 \\
1\end{array}$} & \multicolumn{2}{|c|}{$\stackrel{0.05}{1}$} & \multicolumn{2}{|c|}{$\underset{1}{0.03 *}$} \\
\hline \multirow[t]{2}{*}{$\operatorname{AIR}_{\text {gluc }}(p M)$} & $902 \pm 108$ & $1,703 \pm 408$ & $602 \pm 143$ & $1,173 \pm 322$ & $100 \pm 25$ & $-24 \pm 8$ \\
\hline & \multicolumn{2}{|c|}{$\stackrel{0.07}{1}$} & \multicolumn{2}{|c|}{$\underset{1}{0.05}$} & \multicolumn{2}{|c|}{$\begin{array}{c}\text { NS } \\
1\end{array}$} \\
\hline \multirow[t]{2}{*}{$\operatorname{AIR}_{\text {arg }}(p M)$} & $880 \pm 190$ & $1,730 \pm 488$ & $695 \pm 164$ & $1,659 \pm 284$ & $238 \pm 81$ & $404 \pm 199$ \\
\hline & \multicolumn{2}{|c|}{$\begin{array}{c}0.05 \\
1\end{array}$} & \multicolumn{2}{|c|}{$\begin{array}{c}\text { NS } \\
1\end{array}$} & \multicolumn{2}{|c|}{$\stackrel{0.03^{*}}{1}$} \\
\hline$\Delta \mathrm{AIR}_{\text {ang }} / \Delta \mathrm{G}\left(\mathrm{pM}_{\mathrm{ins}} \cdot \mathrm{mM}^{-1}{ }_{\text {gluc }}\right)$ & $191 \pm 41$ & $361 \pm 85$ & $105 \pm 28$ & $84 \pm 30$ & $15 \pm 7$ & $-16 \pm 8$ \\
\hline
\end{tabular}

$P$ value indicated using Wilcoxon signed rank test; ${ }^{*}$ Significant decrease during NA. 


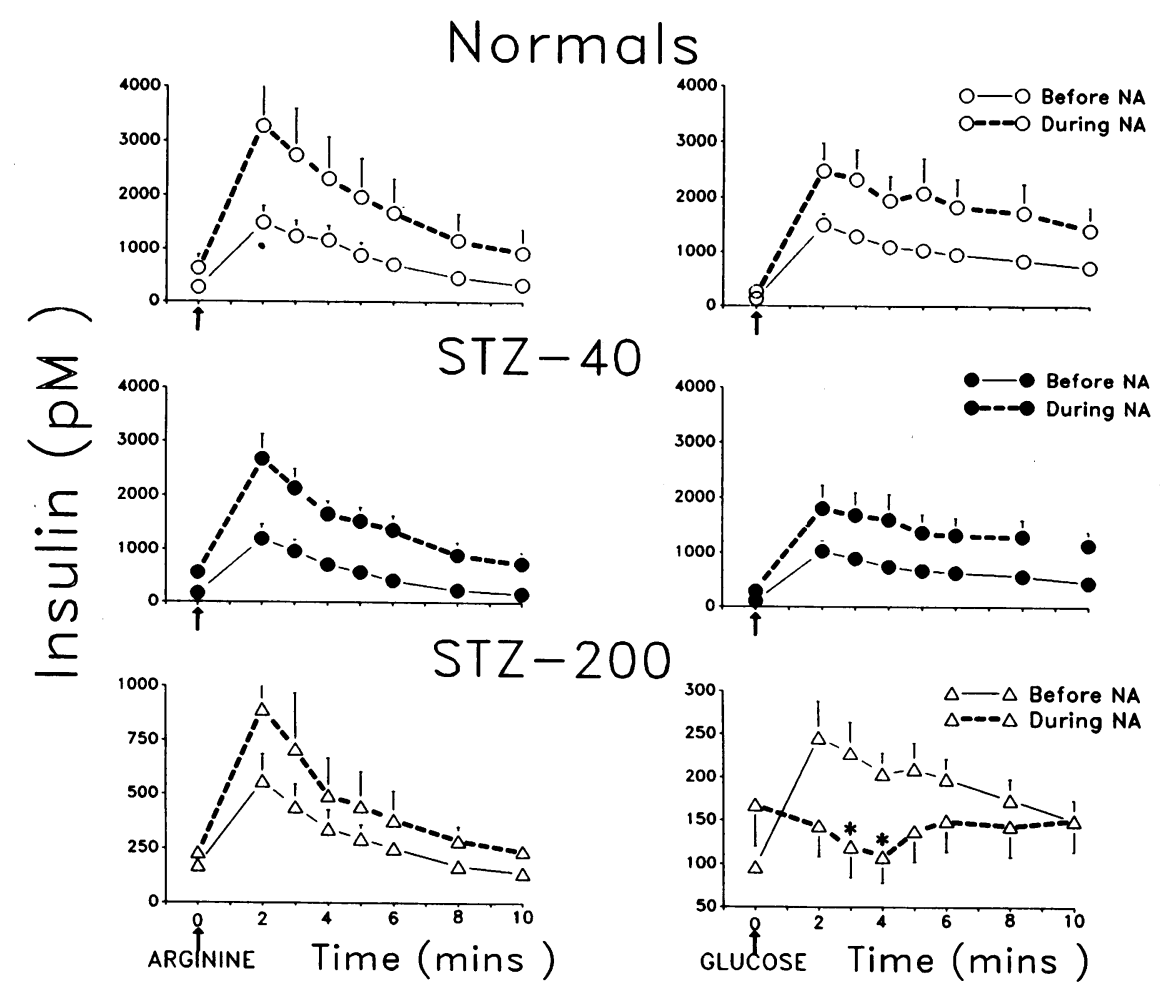

Figure 2. The acute insulin responses to arginine (left panels) and glucose (right panels) at basal glucose in normal animals before NA infusion $(\mathrm{O}-\mathrm{O})$, normal animals during NA infusion (O-- -0 ), upper panel; STZ-40 animals before NA infusion $(\bullet-\bullet)$, STZ-40 animals during NA infusion (•-- $\bullet$ ), middle panel; STZ-200 animals before NA infusion $(\Delta-\Delta)$, and STZ-200 animals during NA infusion $(\Delta---\Delta)$, lower panel.

cose, not significantly higher than the basal insulin before NA, but fell to a nadir of $108 \pm 30 \mathrm{pM}$ at $4 \mathrm{~min}(P<0.05)$ before returning to $150 \pm 36 \mathrm{pM}$ at $10 \mathrm{~min}$.

Glucose homeostasis. The combined effects of insulin resistance and pancreatic $B$ cell dysfunction on fasting plasma glucose and postprandial glycemia (as assessed by $\mathrm{HbA}_{1 \mathrm{c}}$ ) are shown in Fig. 5. For normal animals FPG remained $\sim 5 \mathrm{mM}$

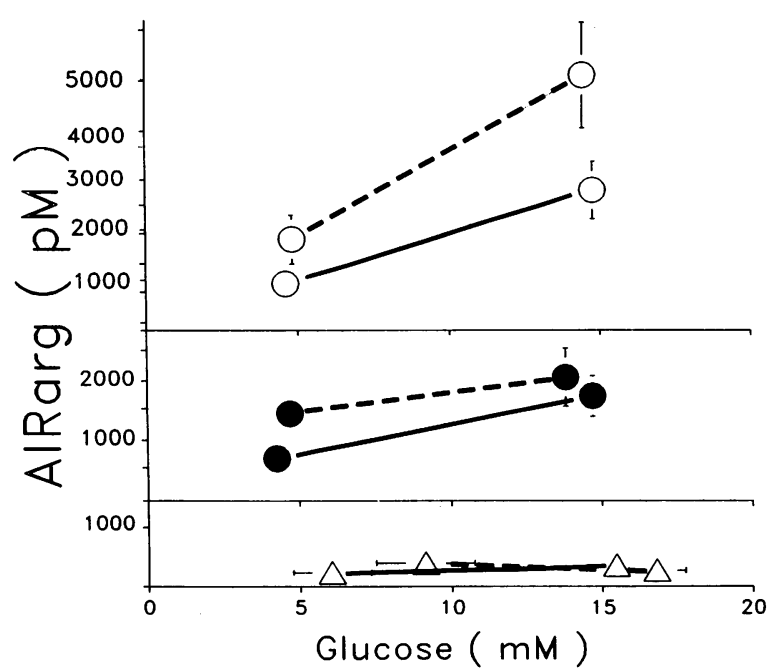

Figure 3. $\mathrm{AIR}_{\text {arg }}$ at two different blood glucose levels in normal animals before NA infusion ( $O-0$ ), normal animals during NA infusion (0- - - O), upper panel; STZ-40 animals before NA infusion $(\bullet-\bullet)$, STZ-40 animals during NA infusion (•-- $\bullet$ ), middle panel; STZ-200 animals before NA infusion $(\Delta-\Delta)$, and STZ-200 animals during NA infusion $(\Delta---\Delta)$, lower panel.
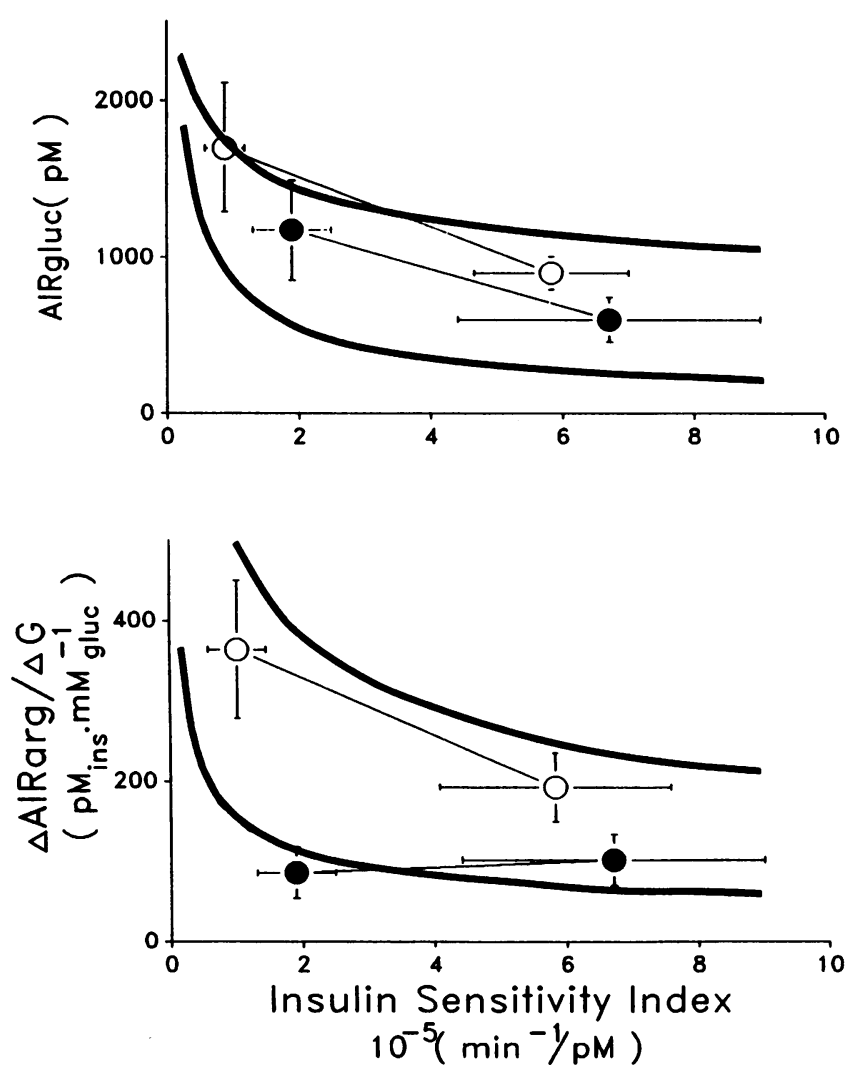

Figure 4. Changes in $\mathrm{AIR}_{\text {uuc }}$ (upper panel) and $\Delta \mathrm{AIR}_{\mathrm{ang}} / \Delta \mathrm{G}$ (lower panel) in response to a drop in insulin sensitivity in normal animals $(\mathrm{O}-\mathrm{O})$ and STZ-40 animals $(\bullet-\bullet)$. The normal range (mean $\pm 1 \mathrm{SD}$ ) for these relationships is indicated by the curved lines (determined from 29 normal baboons). 
before, during, and after $\mathrm{NA}$ infusion. $\mathrm{HbA}_{\mathrm{lc}}$ was $7.1 \pm 0.5 \%$ before NA and showed no significant change during NA treatment (Fig. 5, lower panel). For STZ-40 animals FPG remained $\sim 5 \mathrm{mM}$ before, during, and after NA infusion. $\mathrm{HbA}_{\mathrm{lc}}$ rose steadily, however, from $6.5 \pm 0.3 \%$ before NA to $7.7 \pm 0.4 \%$ at 15 $\mathrm{d}$ and $8.1 \pm 0.5$ at $20 \mathrm{~d}$, values significantly higher than baseline $(P<0.05$, Fig. 5, lower panel $)$. Changes in STZ-200 animals were more striking. FPG rose from $4.9 \pm 0.1 \mathrm{mM}$ before NA to a plateau of $\sim 9 \mathrm{mM}$ from day 8 until the NA infusion was discontinued at $20 \mathrm{~d}(P<0.005) .4 \mathrm{~d}$ after stopping NA the FPG had returned to a value of $4.8 \pm 0.4 \mathrm{mM}$, no different from normal and STZ-40 animals (Fig. 5, upper panel). $\mathrm{HbA}_{1 \mathrm{c}}$ before NA was $6.6 \pm 0.6 \%$ but rose steadily to a value of $8.4 \pm 0.6 \%$ at $10 \mathrm{~d}, 10.3 \pm 1.0 \%$ at $15 \mathrm{~d}$, and $11.8 \pm 1.2 \%$ at $20 \mathrm{~d}$ of NA infusion $(P<0.01$, Fig. 5, lower panel $)$.

\section{Discussion}

Since prolonged treatment with NA induces insulin resistance by an action on peripheral tissue (13-16) and does not affect $B$ cells directly $(22,23)$, we have been able to examine the effects of superimposed insulin resistance on $B$ cell adaptation and glucose homeostasis in the presence of normal and abnormal B cell function. In vivo insulin sensitivity can be measured either by euglycemic hyperinsulinemic clamp techniques or by frequently sampled modified intravenous glucose tolerance tests

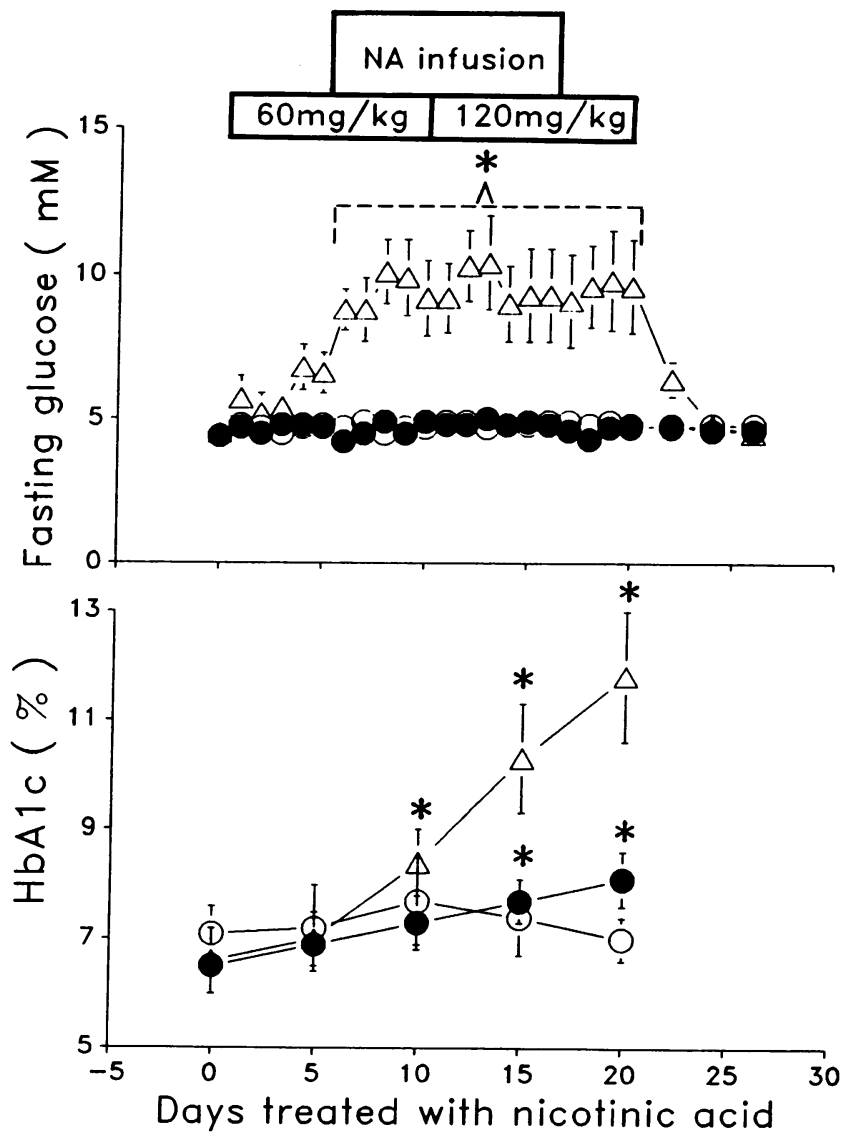

Figure 5. Changes in fasting plasma glucose (upper panel) and $\mathbf{H b A}_{1 \mathrm{c}}$ (lower panel) before, during, and after $20 \mathrm{~d}$ of continuous intravenous infusion of NA in normal (O), STZ-40 (•) and STZ-200 ( $\Delta)$ animals. and computer modeling. These two techniques have been compared extensively in the past decade both in dogs (29) and in humans $(30,31)$. It is now clearly established that there is a wide range in insulin sensitivity between normal individuals using either methodology, that the correlation between the methods is excellent (29-31), and that, when corrections are made so that $S_{1}$ measurements can be expressed in the same units, then $S_{I}$ (by clamp) and $S_{I}$ (by intravenous glucose tolerance test) give equivalent results (31). We chose to use the minimal model using an intravenous glucose tolerance test modified with somatostatin since this markedly improves the precision of the measurement (25) and allows measurement of insulin secretion and insulin sensitivity on the same day. We have shown previously, both in normal humans (3) and baboons (2), that there is an inverse correlation between insulin secretion and insulin sensitivity such that changes in either one can only be fully appreciated when considered in relation to the other $(3,4)$. The baboons in this study showed a profound reduction in insulin sensitivity after 2-3 wk of NA treatment comparable to that seen in human adults (21). Fasting and stimulated insulin levels increased two- to threefold to compensate for the insulin resistance, but stayed within the normal range for animals of that degree of insulin sensitivity (Fig. 4).

We have shown previously in baboons that there is a greater reduction in $\Delta \mathrm{AIR}_{\text {arg }} / \Delta \mathrm{G}$ than $\mathrm{AIR}_{\text {gluc }}$ or $\mathrm{AIR}_{\text {arg }}$ after $\mathrm{STZ}$ treatment (2). This suggests that there is differential sensitivity among these $B$ cell function tests such that $\Delta A I R_{\text {arg }} / \Delta G$ might decline earlier than $\mathrm{AIR}_{\text {eluc }}$, which in turn might decline earlier

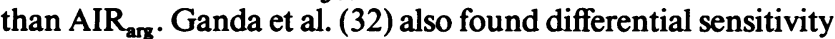
among B cell function tests in human patients with "early" type I diabetes, finding that $\mathrm{AIR}_{\text {gluc }}$ declined earlier than $\mathrm{AIR}_{\text {arg. }}$. In the present study the STZ-40 animals before NA treatment had B cell function which was indistinguishable from the normal animals before NA treatment. During NA infusion their degree of increase in FI, $\mathrm{AIR}_{\text {arg }}$, and $\mathrm{AIR}_{\text {gluc }}$ were very similar to normals during NA infusion. The only B cell function test which failed to compensate was $\Delta A I R_{\text {arg }} / \Delta G$, suggesting again that this is a very early indicator of $B$ cell dysfunction.

In the STZ-200 animals B cell function before NA treatment was significantly impaired compared with normal animals before NA. During NA infusion there was a more pronounced failure of compensatory adaptation with no significant increase in FI or AIR arg $_{\text {, }}$ and even a paradoxical decrease in both $\Delta A \mathrm{AR}_{\text {arg }} / \Delta \mathrm{G}$ and $\mathrm{AIR}_{\text {gluc }}$.

The significance of these compensatory adaptations in B cell function in the presence of insulin resistance can be seen when examining the glycemic responses in these animals. We assessed both fasting plasma glucose and postprandial glycemia (as reflected by $\mathrm{HbA}_{1 \mathrm{c}}$ ) during $20 \mathrm{~d}$ of NA treatment. In general fasting glucose levels are lower in baboons than in humans ( 2 , 33). Nonenzymatic glycosylation of hemoglobin in mammals is determined by three major variables: mean plasma glucose concentration, red cell life span and red cell permeability (33). Since baboons have a higher red cell permeability than humans (33), and a red cell life span of $45 \mathrm{~d}$ compared with $120 \mathrm{~d}$ for human (34), it is possible to see changes in $\mathrm{HbA}_{1 c}$ much earlier in baboons than in humans. In our normal animals, who had normal compensatory increases in both $\Delta A I R_{\text {arg }} / \Delta G$ and $\mathrm{AIR}_{\text {gluc }}$ in response to insulin resistance, fasting glucose and $\mathrm{HbA}_{1 \mathrm{c}}$ remained normal throughout NA treatment. This sug- 
gests that B cell adaptation is complete in these animals and that even insulin resistance of this severity is not sufficient to cause hyperglycemia in the presence of normal B cell function. In STZ-40 animals where $\mathrm{AIR}_{\text {gluc }}$ adaptation was intact but $\Delta \mathrm{AIR}_{\mathrm{arg}} / \Delta \mathrm{G}$ adaptation was markedly impaired, fasting plasma glucose was still maintained during NA treatment but $\mathrm{HbA}_{1 \mathrm{c}}$ rose suggesting postprandial hyperglycemia. This suggests that the physiological importance of the glucose potentiation slope $\left(\Delta \mathrm{AIR}_{\mathrm{arg}} / \Delta \mathrm{G}\right)$ is to enhance insulin secretion postprandially when not only glucose but amino acids and other substrate secretagogues are raised in the blood perfusing the islets. Streptozocin treatment causes a reduction in overall B cell mass (5), reducing overall secretory capacity such that the postprandial response is inadequate and glucose levels remain high. The STZ-200 animals had a more severe B cell lesion as evidenced by inadequate adaptive changes of both $\Delta \mathrm{AIR}_{\text {arg }} / \Delta \mathrm{G}$ and $\mathrm{AIR}_{\mathrm{gluc}}$. These animals developed overt diabetes, during the period of induced insulin resistance, which resolved after NA treatment was discontinued (Fig. 5). These data therefore suggest that, in the presence of significant insulin resistance, the degree of hyperglycemia which develops is proportional to the degree of B cell dysfunction and the ability to compensate for increased demand. Pascoe and Storlein (35) have recently shown that in STZ-treated rats, hyperglycemia only developed when insulin resistance (induced by eating a high fat diet) was superimposed on B-cell dysfunction.

One last finding is worthy of comment. It has been suggested that hyperglycemia itself impairs B cell function (36), and a paradoxical inhibition of insulin secretion after intravenous administration of glucose has been observed in some humans with NIDDM (37-39). Our data from STZ-200 animals during NA infusion support this concept. While normoglycemic, these animals showed an increase in insulin secretion after intravenous glucose, but when NA-induced insulin resistance and inadequate $B$ cell adaptation resulted in hyperglycemia (Fig. 5), insulin secretion after intravenous glucose actually declined. In our study the nadir occurred at $4 \mathrm{~min}$ and had returned to basal by $10 \mathrm{~min}$. Metz et al. (39) using a similar protocol in normal humans and patients with NIDDM found the nadir at 5-10 min with return to baseline by $15 \mathrm{~min}$. These data, and those of our study therefore suggest that, in the presence of a B cell lesion, hyperglycemia exacerbates the degree of $B$ cell dysfunction.

In summary, the present findings demonstrate clearly the relative contributions of pancreatic $B$ cell dysfunction and peripheral insulin resistance to the development of hyperglycemia and show that hyperglycemia itself can further impair B cell function. These data therefore improve understanding of several clinical situations in both NIDDM and IDDM. In NIDDM significant improvements in both insulin action and insulin secretion have been induced by weight reduction or when hyperglycemia is reduced by insulin therapy (39-43). These improvements are maintained for $2 \mathrm{wk}$ after withdrawal of insulin therapy (42).

The acute presentation of IDDM is often due to an intercurrent event which causes insulin resistance to develop in someone with subclinical B cell dysfunction. Because B cell compensation is incomplete, hyperglycemia develops. Insulin therapy may improve the situation in several ways. Exogenous insulin treatment may "rest" the remaining B cells, which may make them less vulnerable to further autoimmune destruction and allow them to recover (44). Another mechanism by which improved glycemia may occur during the honeymoon period could be because insulin treatment improves insulin sensitivity $(45,46)$.

Our data also have implications for the treatment of individuals during the preclinical period of IDDM. Various agents have been suggested for the prevention of IDDM (47). Some of these, like corticosteroids, not only cause decreased insulin sensitivity, but also directly inhibit B cell function (48-50). Cyclosporine has been shown, in dogs, to cause an inhibition of insulin secretion which does not reverse completely on stopping the drug (51). A study of cyclosporine treatment in humans with multiple sclerosis showed no effect on glucose homeostasis and insulin secretion after 1 yr (52). However, such subjects would be expected to have normal pancreatic $B$ cell function. First-degree relatives of type I diabetics under consideration for treatment to prevent clinical IDDM will have some degree of B cell dysfunction before treatment is started. It is unknown whether the use of corticosteroids, azathioprine, cyclosporine or other immunosuppressive agents will have a deleterious effect on B cell function or insulin sensitivity in these subjects. Our data on STZ-treated nonhuman primates suggests that this may well be a useful animal model in which to evaluate proposed immunosuppressive regimens for prevention of IDDM.

\section{Acknowledgments}

We thank Ms. Lynn Spivey for word processing and Mr. Keith Vogel and Mr. John Balch for their technical assistance.

This work was supported by National Institutes of Health grants DK-17047, DK-02456, RR-00166 and by the Department of Veterans Affairs.

\section{References}

1. DeFronzo, R. A. 1988. Lilly Lecture 1987 . The triumvirate: B-cell, muscle liver. A collusion responsible for NIDDM. Diabetes. 37:667-687.

2. McCulloch, D. K., P. K. Raghu, C. Johnston, L. J. Klaff, S. E. Kahn, J. C Beard, W. K. Ward, E. A. Benson, D. J. Koerker, R. N. Bergman, et al. 1988 Defects in B-cell function and insulin sensitivity in normoglycemic streptozocintreated baboons: a model of preclinical insulin dependent diabetes. J. Clin. Endocrinol. Metab. 67:785-792.

3. Johnston, C., P. K. Raghu, D. K. McCulloch, J. C. Beard, W. K. Ward, L. J. Klaff, B. McKnight, R. N. Bergman, and J. P. Palmer. 1987. B-cell function and insulin sensitivity in nondiabetic HLA-identical siblings of insulin dependent diabetics. Diabetes. 36:829-837.

4. McCulloch, D. K., L. J. Klaff, S. E. Kahn, S. L. Schoenfeld, C. J. Greenbaum, R. S. Mauseth, E. A. Benson, G. T. Nepom, L. Shewey, and J. P. Palmer. 1990. Nonprogression of subclinical B-cell dysfunction among first-degree relatives of IDDM patients: 5-yr follow-up of the Seattle Family Study. Diabetes. 39:549-556.

5. McCulloch, D. K., D. J. Koerker, S. E. Kahn, S. Bonner-Weir, and J. P. Palmer. 1990. In vivo beta cell function tests accurately reflect residual beta cell mass in streptozocin-treated baboons. Clin. Res. 38:123A. (Abstr.)

6. Carlson, L. A., and L. Orö. 1962. The effect of nicotinic acid on the plasma free fatty acids. Acta Med. Scand. 172:641-645.

7. Pereira, J. N. 1967. The plasma free fatty acid rebound induced by nicotinic acid. J. Lipid Res. 8:239-244.

8. Pinter, E. J., and C. J. Pattee. 1967. Biphasic nature of blood glucose and free fatty acid changes following intravenous nicotinic acid in man. J. Clin. Endocrinol. Metab. 27:440-443.

9. Nye, E. R., and H. Buchanan. 1969. Short-term effect of nicotinic acid on plasma level and turnover of free fatty acids in sheep and man. J. Lipid Res. 10:193-196.

10. Gross, R. C., and L. A. Carlson. 1968. Metabolic effects of nicotinic acid in acute insulin deficiency in the rat. Diabetes. 17:353-361.

11. Davidson, M. B., and J. M. Bernstein. 1973. The effect of nicotinic acid on growth hormone-induced lipolysis and glucose intolerance. J. Lab. Clin. Med. 81:568-576. 
12. Reaven, G. M., H. Chang, and B. B. Hoffman. 1988. Additive hypoglycemic effects of drugs that modify free-fatty acid metabolism by different mechanisms in rats with streptozocin-induced diabetes. Diabetes. 37:28-32.

13. Gundersen, K., and H. V. Demissianos. 1969. The effects of 5-methylpyrazole-3-carboxylic acid $(\mathrm{U}-19,425)$ and nicotinic acid (NA) on free fatty acids (FFA), triglycerides (TG) and cholesterol in man. In Drugs Affecting Lipid Metab olism. W. L. Holmes, L. A. Carlson, and R. Paoletti, editors. Adv. Exp. Med. Biol 4:213-226.

14. Randle, P. J., P. B. Garland, C. N. Hales, and E. A. Newsholme. 1963. The glucose fatty-acid cycle: its role in insulin sensitivity and the metabolic disturbances of diabetes mellitus. Lancet. $i: 785-789$.

15. Hales, C. N., and P. J. Randle. 1963. Effects of low-carbohydrate diet and diabetes mellitus on plasma concentrations of glucose, non-esterified fatty acid and insulin during oral glucose-tolerance tests. Lancet. $i: 790-794$.

16. Hollobaugh, S. L., M. Tzagournis, R. L. Folk, F. A. Kruger, and G. J. Hamwi. 1968. The diabetogenic action of human growth hormone: glucose-fatty acid interrelationships. Metab. Clin. Exp. 17:485-491.

17. Miettenen, T. A., M-R. Taskinen, R. Pelkonen, and E. A. Nikkila. 1969 Glucose tolerance and plasma insulin in man during acute and chronic administration of nicotinic acid. Acta Med. Scand. 186:247-253.

18. Marks, V., D. Frizel, R. G. Twycross, and K. S. Buchanan. 1971. Effect of B-pyridylcarbinol on glucose tolerance, plasma glucagon, insulin and growth hormone in man. In Metabolic Effects of Nicotinic Acid and Its Derivatives. K. F. Gey and L. A. Carlson, editors. Hans Huber, Bern, Switzerland. 961-976.

19. Gaut, Z. N., R. Pocelinko, H. M. Solomon, and G. B. Thomas. 1971. Oral glucose tolerance, plasma insulin, and uric acid excretion in man during chronic administration of nicotinic acid. Metab. Clin. Exp. 20:1031-1035.

20. Lithell, H., B. Vessby, and K. Hellsing. 1982. Changes in glucose tolerance and plasma insulin during lipid-lowering treatment with diet, clofibrate and niceritrol. Atherosclerosis. 43:177-184.

21. Kahn, S. E., J. C. Beard, M. W. Schwartz, W. K. Ward, H. L. Ding, R. N. Bergman, G. J. Taborsky, Jr., and D. Porte, Jr. 1989. Increased B-cell secretory capacity as mechanism for islet adaptation to nicotinic acid-induced insulin resistance. Diabetes. 38:562-568.

22. Loffler, G., and I. Trautschold. 1971. Influence of nicotinic acid on insulin secretion in vivo and in vitro. In Metabolic Effects of Nicotinic Acid and Its Derivatives. K. F. Gey and L. A. Carlson, editors. Hans Huber, Bern, Switzerland. 993-937.

23. Malaisse, W. J., F. Malaisse-Lagae, and D. Mayhew. 1967. A possible role for the adenylcyclase system in insulin secretion. J. Clin. Invest. 46:1724-1734.

24. Bergman, R. N., Y. Z. Ider, C. R. Bowden, and C. Cobelli. 1979. Quantitative estimation of insulin sensitivity. Am. J. Physiol. 236:E667-E677.

25. Yang, Y. J., J. H. Youn, and R. N. Bergman. 1987. Modified protocols improve insulin sensitivity estimation using the minimal model. Am. J. Physiol. 252:E595-E602.

26. Morgan, C. R., and A. Lazarow. 1963. Immunoassay of insulin two antibody techniques system. Diabetes. 12:115-121.

27. Pecoraro, R. E., R. J. Graf, J. B. Halter, H. Beiter, and D. Porte, Jr. 1979. Comparison of a colorimetric assay for glycosylated hemoglobin with ion-exchange chromatography. Diabetes. 28:1120-1125.

28. Halter, J. B., R. J. Graf, and D. Porte, Jr. 1979. Potentiation of insulin secretory responses by plasma glucose in man: Evidence that hyperglycemia in diabetes compensates for impaired glucose potentiation. J. Clin. Endocrinol. Me tab. 48:946-954.

29. Finegood, D. T., G. Pacini, and R. N. Bergman. 1984. The insulin sensitivity index: correlation in dogs between values determined from the intravenous glucose tolerance test and the euglycemic glucose clamp. Diabetes. 33:362-368.

30. Beard, J. C., R. N. Bergman, W. K. Ward, and D. Porte, Jr. 1986. The insulin sensitivity index in nondiabetic man: correlation between clamp-derived and IVGTT-derived values. Diabetes. 35:362-369.

31. Bergman, R. N., R. Prager, A. Volund, and J. M. Olefsky, 1987 Equivalence of the insulin sensitivity index in man derived by the minimal model method and the euglycemic glucose clamp. J. Clin. Invest. 79:790-800.
32. Ganda, O. P., S. Srikanta, S. J. Brink, M. A. Morris, R. E. Gleason, J. S. Soeldner, and G. S. Eisenbarth. 1984. Differential sensitivity to B-cell secretagogues in "early," type I diabetes mellitus. Diabetes. 33:516-521.

33. Higgins, P. J., R. L. Garlick, and H. F. Bunn. 1982. Glycosylated hemoglobin in human and animal red cells. Diabetes. 31:743-748.

34. Berlin, N., and P. Berk. 1975. The biological life of the red cell. In The Red Blood Cell. D. M. Surgenor, editor. Academic Press, Inc., New York. 958-1020.

35. Pascoe, W. S., and L. H. Storlein. 1990. Inducement of fat feeding of basal hyperglycemia in rats with abnormal B-cell function: model for study of etiology and pathogenesis of NIDDM. Diabetes. 39:226-233

36. Unger, R. H., and S. Grundy. 1985. Hyperglycemia as an inducer as well as a consequence of impaired islet cell function and insulin resistance: implications for the management of diabetes. Diabetologia. 28:119-121.

37. Seltzer, H. S., E. W. Allen, A. L. Herron, Jr., and M. T. Brennan. 1967. Insulin secretion in response to the glycemic stimulus: relation of delayed initial release to carbohydrate in tolerance in mild diabetes mellitus. J. Clin. Invest. 46:323-335.

38. Lerner, R. L, and D. Porte, Jr. 1972. Acute and steady state insulin responses to glucose in nonobese diabetic subjects. J. Clin. Invest. 51:1624-1631.

39. Metz, S. A., J. B. Halter, and R. P. Robertson. 1979. Paradoxical inhibition of insulin secretion by glucose in human diabetes mellitus. J. Clin. Endo crinol. Metab. 48:827-835.

40. Scarlett, J. A., R. S. Gray, J. Griffin, J. M. Olefsky, and O. G. Kolterman 1982. Insulin treatment reverses the insulin resistance of type II diabetes mellitus. Diabetes Care. 5:353-363.

41. Vague, O., and J.-P. Moulin. 1982. The defective glucose sensitivity of the B-cell in non-insulin-dependent diabetes: improvement after twenty hours of normoglycemia. Metab. Clin. Exp. 31:139-142.

42. Andrews, W. J., B. Vasquez, M. Nagulesparan, I. Klimes, J. Foley, R. Unger, and G. M. Reaven. 1984. Insulin therapy in obese, non-insulin-dependent diabetes induces improvements in insulin action and secretion that are maintained for two weeks after insulin withdrawal. Diabetes. 33:634-642.

43. Garvey, W. T., J. M. Olefsky, J. Griffin, R. F. Hamman, and O. G. Kolterman. 1985. The effect of insulin treatment on insulin secretion and insulin action in type II diabetes mellitus. Diabetes. 34:222-234.

44. Shah, S. C., J. I. Malone, and N. W. Simpson. 1989. A randomized trail of intensive insulin therapy in newly diagnosed insulin-dependent diabetes mellitus. N. Engl. J. Med. 320:550-554.

45. Lager, I., P. Lonroth, H. von Schenck, and U. Smith. 1983. Reversal of insulin resistance in type I diabetes after treatment with continuous subcutaneous insulin infusion. Br. Med. J. 287:1661-1666.

46. Revers, R. R., O. G. Kolterman, J. A. Scarlett, R. S. Gray, and J. M. Olefsky. 1984. Lack of in vivo insulin resistance in controlled insulin-dependent, type I, diabetic patients. J. Clin. Endocrinol. Metab. 58:353-361.

47. Maclaren, N. K., W. J. Riley, W. E. Winter, and J. H. Silverstein. 1987. Is insulin-dependent diabetes mellitus a preventable disease? Clin. Invest. Med. 10:444-449.

48. Barseghian, C., and R. Levine. 1980. Effect of corticosterone on insulin and glucagon secretion by the isolated perfused rat pancreas. Endocrinology. 106:547-552.

49. Kalhan, S. C., and P. A. J. Adam. 1975. Inhibitory effect of prednisone on insulin secretion in man: model for duplication of blood glucose concentration. $J$. Clin. Endocrinol. Metab. 41:600-610.

50. Marco, J., C. Calle, D. Roman, M. Diaz-Fierros, M. L. Villaneuva, and I. Valverde. 1973. Hyperglucagonism induced by glucocoricoid treatment in man. N. Engl. J. Med. 288:128-131.

51. Feldman, E. C., K. Polonsky, and R. Alejandro. 1988. Cyclosporine (CSA) interfers with insulin/C-peptide secretion in healthy beagles. Diabetes. 37(Suppl. 1):103A. (Abstr.)

52. Robertson, R. P., G. Franklin, and L. Nelson. 1989. Glucose homeostasis and insulin secretion during chronic treatment with cyclosporin in nondiabetic humans. Diabetes. 38(Suppl. 1):99-100. 